\title{
粪便RNA的检测在大肠癌早期诊断中的应用
}

\author{
乞宗泰 ${ }^{1}$, 邓黎莉 ${ }^{1}$, 黄欢 ${ }^{2}$, 赵建华 ${ }^{3}$, 周国华 ${ }^{1,2}$ \\ 1. 中国药科大学生命科学与技术学院, 南京 210009; \\ 2. 华东医学生物技术研究所, 南京 210002; \\ 3. 江苏省肿瘤医院, 南京 210000
}

摘要：大肠癌是胃肠道恶性肿瘤之一, 在我国大肠癌的发病率和死亡率呈上升趋势。由于死亡率与大肠癌的诊 断时间密切相关, 因此早期诊断大肠癌尤为重要。但是目前临床常规沴断方法存在一定的局限性, 难以实现大 肠癌的早期诊断。粪便 RNA 检测技术是近年来发展的基于分子水平的早期无创检测大肠癌的技术，与常规检 测技术包括结肠镜检测、大便隐血检测和粪便 DNA 突变检测相比, 粪便 RNA 检测具有成本低和灵敏度高等优 点, 并可同时分析多种基因表达量和动态监测肿瘤进展。文章介绍了粪便 RNA 检测的可行性, 系统阐述了用于 粪便 RNA 检测的特异性基因、粪便 RNA 的提取方法和粪便 RNA 的检测技术, 并对粪便 RNA 检测技术在大肠 癌早期诊断中的进一步应用进行了展望。

关键词：大肠癌；粪便RNA；早期诊断

\section{Advances in early diagnosis of colorectal cancer based on detection of RNAs in stool}

\author{
QI Zong-Tai ${ }^{1}$, DENG Li-Li ${ }^{1}$, HUANG Huan ${ }^{2}$, ZHAO Jian-Hua ${ }^{3}$, ZHOU Guo-Hua ${ }^{1,2}$ \\ 1. College of Life Science and Technology, China Pharmaceutical University, Nanjing 210009, China; \\ 2. Huadong Research Institute for Medicine and Biotechnics, Nanjing 210002, China; \\ 3. Jiangsu Cancer Hospital, Nanjing 210000, China
}

\begin{abstract}
Colorectal cancer (CRC) is one of the most malignant cancers in gastrointestinal tract. In China, there are increasing rates of morbidity and mortality for CRC. As the mortality is closely related to the stage of disease at time of diagnosis, early diagnosis of CRC is important. However, current techniques used for clinical diagnosis have limitations which made them difficult to achieve the early diagnosis. The detection of RNAs in stool is a newly developed noninvasive technique for early diagnosis of CRC at molecular levels. Compared with the techniques including colonoscopy, fecal occult-blood test and stool DNA-based mutation detection, diagnosis based on the detection of RNAs in stool has the advantages of low-cost and high sensitivity. Moreover, stool RNA-based techniques are able to analyze multiplexed gene expression simultaneously and monitor cancer progression dynamically. This paper introduced the feasibility of stool RNA analysis, and systematically reviewed the genes associated with stool RNA analysis, methods of RNA isolation from stool sample, and techniques for gene expression analysis in stool RNA. Finally, further applications of stool RNA-based techniques for early diagnosis of CRC were briefly discussed.
\end{abstract}

Keywords: colorectal cancer; stool RNA; early diagnosis

收稿日期: 2010-03-23; 修回日期: 2010-04-23

基金项目:南京市科技发展计划项目指令性计划(编号：200801087)资助

作者简介:乞宗泰(1984-), 男, 硕士研究生, 专业方向：分子遗传学。Tel: 025-84514223; E-mail: qizt1984@163.com

通讯作者:周国华(1964-), 男, 博士生导师, 研究方向：分子遗传学。E-mail: ghzhou@nju.edu.cn 
大肠癌是胃肠道常见的恶性肿瘤之一, 具有潜 伏时间长、早期不易诊断等特点。在我国, 大肠癌 的发病率和死亡率呈上升趋势。大肠癌治疗的关键 在于早期诊断, 早有调查结果 ${ }^{[1]}$ 显示早期诊断大肠 癌有助于降低其发病率和死亡率。但是, 由于大肠 癌早期常无明显临床症状, 就诊时大部分已进展为 中晚期。因此, 探索对高危人群的早期诊断方法显 得尤为重要。

目前, 大肠癌早期诊断的方法有结肠镜检测 (Colonoscopy)、大便隐血检测(Fecal occult blood test, FOBT)、粪便DNA突变检测和粪便RNA特异性基因 检测等。结肠镜检测 ${ }^{[2]}$ 被认为是诊断结直肠癌的金 标准, 但是它为侵入性检查, 需要肠道准备, 有发 生出血及穿孔危险。大便隐血检测 ${ }^{[3,4]}$ 虽然为非侵入 性检测，但是检测前需饮食控制，并且对于篮查大 肠癌而言, 粪便隐血是一种不灵敏和非特异性的标 记物。

随着分子生物学的发展和分子检测水平的不断 提高, 大肠癌的早期诊断领域出现了基于分子水平 的无创检测技术，包括粪便DNA 突变检测和粪便 RNA特异性基因检测。这种无创检测技术，与粪便 隐血检测相比, 选取的粪便标记物更准确, 能够极 大地提高检测的灵敏度和特异性。近年来发展的粪 便DNA突变检测技术有很多, 包括核酸内切酶 V 结 合酶连检测技术 $[5]$ 、数字化PCR技术 $[6]$ 、数字化融解 曲线技术 ${ }^{[7]}$ 等。但是, 这些技术的成本都较高, 其中 一些技术并不适用于DNA微突变(突变率小于 $0.1 \%$ ) 的检测, 而且目前已知与大肠癌和乳腺癌相关的
DNA突变位点数目多达 90 个, 这些突变位点在不同 个体中存在较大差异 ${ }^{[8]}$ 。因此, 需要对每个DNA突变 位点进行检测才能得到较好的检出率, 这样使得粪 便DNA突变检测的方法变得费时费力。

粪便RNA的检测作为新近发展的大肠癌筛查技 术，与其他技术尤其是粪便DNA突变检测技术相比 具有一定的优势, 主要体现在: (1) 检测成本低, 只 需普通的PCR仪或者实时苂光定量PCR仪便可以满 足检测要求; (2) 检测基因数量多, 可同时联合多种 基因进行检测，提高检出率 ${ }^{[9]}$; (3) 通过基因相对表

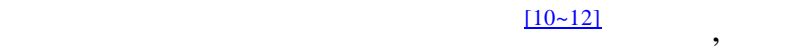
RNA的检测已经成为临床早期诊断大肠癌的研究热 点之一。本文对粪便RNA的检测在大肠癌诊断中的 研究进展进行综述。

\section{1 粪便RNA检测的可行性}

正常成人结肠粘膜大约含有 $5 \times 10^{10}$ 个上皮细胞, 其更新速度很快, 约以每小时 $1 \%$ 的速度更新。这 样, 每天大约有 $10^{10}$ 个正常上皮细胞脱落入肠腔, 并随粪便排出。结肠粘膜上生长旺盛的肿瘤细胞则 更新更快, $1 \mathrm{~cm}$ 大小的肿瘤每天脱落细胞数超过 $10^{9}$ 个。癌变结肠粘膜和正常结肠粘膜中上皮细胞的状 态见图 $1^{[13]}$ 。肿瘤特异性的脱落细胞随粪便排出体 外, 就为大肠癌粪便RNA的检测提供了材料源泉。 采用适当的方法把粪便中肿瘤特异性的RNA 提取 出来, 再通过分子生物学方法分析粪便RNA中相关 癌基因的相对表达量变化, 就可以进行大肠癌的早 期诊断和篮查。

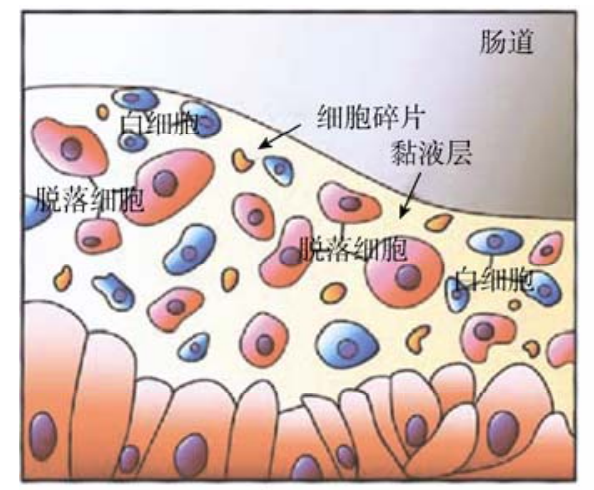

A

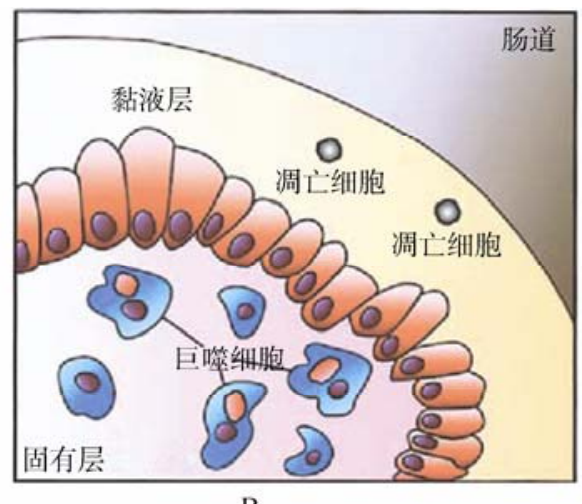

B

图 1 癌变结肠粘膜(A)和正常结肠粘膜(B)中上皮细胞状态的比较

癌变的结肠粘膜上皮包含有大量脱落细胞(Colonocyte, C)和白细胞(Leucocyte, L); 正常的结肠粘膜上皮只有少量调亡细胞(Apoptotic cell, AC)。 


\section{2 粪便RNA的特异性基因标记}

分子生物学研究表明 ${ }^{[13]}$, 大肠癌是一个涉及原 癌基因激活、抑癌基因失活的多基因和多阶段的积 累过程。大肠癌发生发展伴随着多种基因的改变, 选择特异性的基因作为大肠癌诊断的基因标记是十 分必要的。

\section{$2.1 C O X-2$ 基因}

COX-2(Cyclooxygenase 2)属于环氧化酶, 是前 列腺素合成过程中一种重要的诱导酶。COX-2 在正 常组织中几乎不表达, 但能被生长因子、细胞因子、 肿瘤促进因子等诱导表达, 并可刺激肿瘤生长和转 移、抑制细胞凋亡等 ${ }^{[14]}$ 。大量研究表明 ${ }^{[14 ~ 16]}$, 约 $80 \%$ 的大肠癌患者有 $C O X-2$ 基因的高表达, 说明 $C O X-2$ 基因与大肠癌发生发展有密切联系。Kanaoka等 ${ }^{[17]}$ 首 次应用巢式逆转录PCR技术(Nested-RT-PCR)检测到 了大肠癌患者粪便RNA中 $C O X-2$ 基因的表达。其结 果显示, 4 例Dukes' A期患者和 14 例Dukes’ B期患者 中分别有 3 例和 11 例 COX-2 基因的表达为阳性, 11 例Dukes' C 期和D期患者中有 10 例为阳性，22 例正 常人 COX-2 基因的表达均为阴性, 说明对粪便 RNA 中的 $C O X-2$ 基因进行检测具有较高的灵敏度和特 异性。

\section{$2.2 \quad M M P-7$ 基因}

$M M P($ Matrix metallo proteinases)是一类近年来 引人注目的蛋白水解酶, 在肿瘤侵袭过程中发挥重 要作用, 成为肿瘤研究的热点 ${ }^{[18]}$ 。MMP7 是 $M M P$ 家 族中分子量最小的成员, 具有高度蛋白溶解能力及 广泛的底物特异性, 可激活多种细胞外基质, 在肿 瘤的侵袭与转移过程中起重要作用。Takai等 ${ }^{[19]}$ 利用 Nested-RT-PCR在 62 例大肠癌患者粪便RNA中检测 出 40 例存在MMP-7 基因的表达, 其中Dukes' A期、 $B$ 期、C 期和 D期患者的检测灵敏度分别为 $38 \%$ 、 78\%、73\%和 55\%，并指出联合MMP-7 基因和COX-2 基因进行检测可进一步提高检测灵敏度，对Dukes' $A$ 期和B期患者的检测灵敏度可达 93\%。

\section{$2.3 c-m y c$ 基因}

$c-m y c$ 是原癌基因, 其编码的核蛋白属于细胞核 内的DNA结合蛋白。c-myc基因是一种可使细胞无限
增殖, 促进细胞分裂的基因, 它参与细胞调亡, 并 与肿瘤的发生、发展有关 ${ }^{[20]}$ 。Lagerholm等 ${ }^{[211}$ 收集粪 便中的脱落细胞, 提取RNA后, 通过逆转录聚合酶 链式反应(RT-PCR)来分析 $c-m y c$ 基因的相对表达量。 其结果显示, $78.6 \%$ 的大肠癌患者粪便RNA中 c-myc 基因的表达为阳性，而在正常人的粪便RNA中只有 13.3\%为阳性, 并且大肠癌患者和正常人的 $c-m y c$ 基 因相对表达量存在显著差异。

\section{$2.4 C D 44$ 基因}

$C D 44$ 是一种细胞表面粘附因子, 参与细胞和 细胞、细胞和基质之间的特异性粘附过程。CD44 作为跨膜透明质酸受体, 直接影响到肿瘤细胞与细 胞外基质的结合能力, 通过选择性剪接可形成 10 种 剪接变异体 $(C D 44 v)$, 其中 v6 外显子的变异体 $C D 44 v 6$ 与大肠肿瘤的发生、发展和侵袭、转移行为 密切相关 ${ }^{[22]}$ 。Yamao等 ${ }^{[23]}$ 分离粪便中的脱落细胞, 提取RNA后，应用RT-PCR和Southern杂交发现，68\% 的大肠癌患者 $C D 44 v 6$ 基因的表达为阳性，60\%的大 肠癌患者 CD44v10 基因的表达为阳性。CD44v6 基因 和CD44v10 基因用于检测Dukes’ A 期患者的灵敏度 均为 $62.5 \%$, 用于检测Dukes' B期和C期患者的灵敏 度分别为 $70.6 \%$ 和 $58.8 \%$ 。

\subsection{MicroRNA}

MicroRNA(miRNA)是一种包含 19 25 个碱基的 单链非编码小分子 RNA, 其在个体生长发育、细胞 增殖凋亡、炎症和肿瘤等多种生理病理过程中起着 十分重要的作用。在许多肿瘤细胞, 包括大肠癌细 胞中都能观察到miRNA表达谱的改变 ${ }^{[24]}$ 。Ahmed等 [25]应用基因芯片检测大肠癌患者粪便RNA中 15 种 miRNA的表达量的变化, 结果表明其相对表达量在 大肠癌患者和正常人之间存在差异, 并指出联合检 测miRNA和mRNA表达量的变化可以为大肠癌的早 期诊断提供一个高敏感度和特异性的个体化诊断方 案。

除上述基因外，Yajima等[26]还报道了 85 种可以 作为大肠癌早期检测的基因，并指出联合多种基因 检测可以提高检出率。不同基因的检测过程和检测 结果的对比见表 1 。随着分子生物学的发展, 基因检 测水平正在逐步提高, 利用粪便RNA进行大肠癌早 期诊断将成为一种有效的无创篮查手段。 
表 1 不同基因的检测过程和检测结果对比

\begin{tabular}{llll}
\hline 基因名称 & 粪便 RNA 提取方法 & 粪便 RNA 检测方法 & 检测结果 \\
\hline$C O X-2$ & 直接提取粪便中 RNA & RT-PCR & 灵敏度 $90 \%$, 特异性 $100 \%$ \\
$M M P-7$ & 直接提取粪便中 RNA & RT-PCR & 灵敏度 $65 \%$, 特异性 $100 \%$ \\
$c-m y c$ & 富集肿瘤细胞后提取 RNA & RT-PCR & 灵敏度 $64 \%$, 特异性 $100 \%$ \\
$C D 44 v 6$ & 富集肿瘤细胞后提取 RNA & RT-PCR & 灵敏度 $68 \%$ \\
miRNA & 富集肿瘤细胞后提取 RNA & 基因芯片 & 患者和正常人存在显著差异 \\
联合 4 种基因 $^{(1)}$ & 富集肿瘤细胞后提取 RNA & 实时苂光定量 PCR & 灵敏度 $58.3 \%$, 特异性 $88.1 \%$ \\
联合 9 种基因 $^{(2)}$ & 富集肿瘤细胞后提取 RNA & 基因芯片 & 灵敏度 $78 \%$, 特异性 $100 \%$ \\
\hline
\end{tabular}

(1) 4 种基因为: TP53, MMP7, MYBL2, COX-2;

(2) 9 种基因为: PAP, REG1A, DEPE, SEPP1, RPL27A, ATP1B1, EEF1A1, SFN, PRS11。

\section{3 粪便样本的运输和保存}

在粪便RNA检测过程中，粪便样本的运输和保 存非常重要。粪便样本的成分十分复杂, 包括胆酸、 细菌、食物残渣等 ${ }^{[27]}$ 。这些成分一方面会导致脱落 细胞的死亡，使其内部的RNA随之降解; 另一方面 这些成分中含有丰富的核糖核酸酶, 也会使分离得 到的RNA降解。而且粪便样本离体后，在不同的保 存时间和保存温度下，其脱落细胞的相对数量不 同。由图 2[28]可见，较低的保存温度和较短的保存时 间可以得到相对较多的脱落细胞。鉴于以上分析, 选择合适的方法运输和保存粪便样本是进行粪便 RNA检测的重要前提。

从目前报道的文献看, 为了减少脱落细胞的死 亡和RNA的降解, 粪便样本一般在低温 $\left(0^{\circ} \mathrm{C} \sim 4^{\circ} \mathrm{C}\right)$ 条件 下进行运输。并且从粪便样本的离体到粪便RNA的提 取, 整个过程不宜超过 4 小时 ${ }^{[29]}$ 。Ahmed等 ${ }^{[10]}$ 指出在 运输过程中可以将粪便样本保存在Ambion公司的
RNALate溶液中, 这样能够减少RNA的降解现象, 有助于得到高质量的粪便 RNA。如果长期保存粪便样 本, 则需要将其冻存于液氮或者 $-70^{\circ} \mathrm{C}$ 冰箱中, 但由于 粪便样本成分较为复杂, 因此并不建议长期保存。

\section{4 粪便RNA的提取方法}

目前用于粪便 RNA 的提取方法主要两种: 先富集肿瘤特异性的脱落细胞, 然后再提取脱落细 胞中的 RNA; (2) 直接从粪便中提取脱落细胞 RNA。

\section{1 富集肿瘤细胞后提取RNA}

常见的粪便RNA提取方法是先富集肿瘤特异性

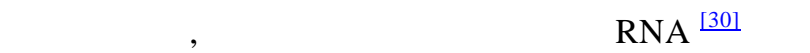
先，通过免疫磁珠富集上皮细胞技术富集粪便中的肿 瘤细胞。该技术是将抗原-抗体特异结合技术与磁珠 技术相结合来实现脱落细胞的富集, 即在磁珠表面 包被抗体, 该抗体可以与脱落细胞膜表面表达的抗 原特异结合, 通过磁铁吸附结合有上皮细胞的磁
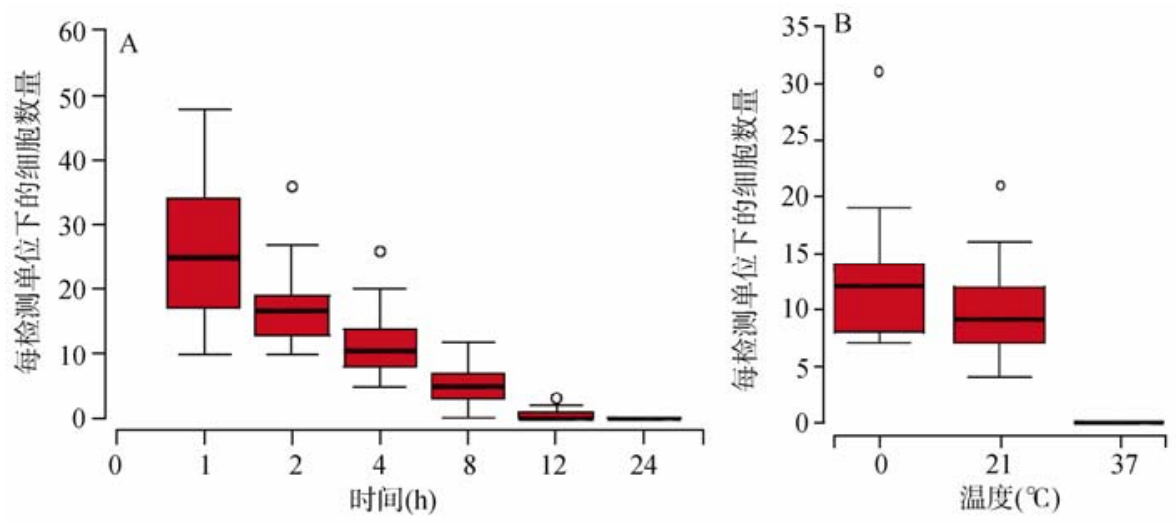

图 2 不同保存时间(A)和温度(B)下粪便脱落细胞的数量变化

将 $10^{6}$ 个 HT-29 细胞加入 $30 \mathrm{~g}$ 正常人的新鲜粪便, 在不同时间段和温度下进行脱落细胞提取和计数, 实验平行操作 3 次。柱状图顶端和底端 指示预计的波动范围，柱状图粗体部分指示四分位差，水平黑线指示中值，圆圈指示超出预计波动范围的数值。 
珠, 从而使得脱落细胞与其他细胞分离, 达到富集 脱落细胞的目的。然后, 再用常规方法提取脱落细 胞中的 RNA 便可以获得粪便 RNA。

2007 年, Ahmed等 ${ }^{[10]}$ 利用这种先富集细胞再提取 RNA的方法成功分析了大肠癌患者粪便RNA中 8 种 癌基因(IGF2、FLNA、TGF、CKS2、CSE1L、DPEP1、 $K L K I O 、 C X C L 3)$ 的相对表达量变化, 并指出这 8 种 基因相对表达量的高低与大肠癌的Dukes分期相关, 可以动态监测肿瘤的进展。2008 年, Koga等 ${ }^{[9]}$ 同样利 用这种提取方法, 联合 4 种癌基因(TP53、MMP7、 $M Y B L 2 、 C O X-2)$ 进行大肠癌检测, 整个方法灵敏度 为 $58.3 \%$, 特异性为 $88.1 \%$ 。

这种富集肿瘤细胞后提取 RNA 的技术可以使 提取得到的 RNA 纯度较高, 但是其所使用的免疫磁 珠价格昂贵, 而且整个粪便 RNA 的提取过程包括多 次抗原抗体结合反应, 时间长、操作步骤多, 使得粪 便 RNA 的提取过程变得复杂和繁琐并且难以广泛 应用。

\section{2 直接提取粪便中 RNA}

鉴于先富集肿瘤细胞再提取RNA的过程较为复 杂和繁琐, 研究人员试图直接从粪便样本中进行 RNA的提取来简化整个操作流程。2004 年, Kanaoka 等 ${ }^{[17]}$ 在Chomczynski等 ${ }^{[31]}$ 提出的RNA一步提取法的 基础上进行改进, 即用含有异硫氰酸胍和苯酚的试 剂(Isogene)结合QIAGEN公司的RNeasy提取试剂盒 来进行粪便RNA的提取。具体过程: 首先, 将粪便样 本和Isogene试剂混合, 该试剂一方面能裂解粪便内 的脱落细胞使其RNA释放出来，另一方面也可以有 效地抑制粪便内的RNA酶对RNA的降解作用。然后, 离心去除粪便内的各种杂质成分, 用氯仿抽提上清 并离心使其分层。最后, 将得到的水相和等体积的 $70 \%$ 乙醇混合, 再按照QIAGEN公司 RNA提取操作 的说明进行柱上提取。作者利用该方法提取了 51 例 粪便样本的RNA, 并通过 Nested-RT-PCR分析了大
肠癌患者和正常人的 $C O X-2$ 基因相对表达量的差 异。2005 年, Yang等 ${ }^{[24]}$ 同样直接提取粪便中的RNA 并对其进行CK19 基因相对表达量的分析。该研究小 组是用异硫氰酸胍的缓冲液和Geneaid公司的RNA 提取试剂盒来进行粪便 RNA 提取, 其原理和 Kanaoka等 ${ }^{[17]}$ 相似。

这种直接从粪便中提取 RNA 的方法与富集肿 瘤细胞后提取 RNA 的方法相比，具有快速、简便的 优点, 但是由于直接从粪便中提取 RNA 的方法没有 富集粪便脱落细胞的步骤, 其 RNA 的纯度不如富集 肿瘤细胞后提取得到的 RNA 纯度高。这两种粪便 RNA 提取方法的优缺点对比见表 2。

目前无论是富集肿瘤细胞后提取 RNA 还是直 接提取粪便中 RNA, 不同研究人员的操作步骤和使 用的试剂都不尽相同, 所得到的 RNA 质量也有所差 异。这样, 使得研究结果难以统一起来做系统分析。 因此，建立一种或者几种标准的粪便 RNA 提取方法 是必要的。粪便 RNA 提取操作的标准化不仅有利于 系统分析数据, 而且可以确保粪便 RNA 的提取质量, 加快粪便 RNA 在大肠癌早期诊断中的应用。

\section{5 粪便RNA的检测技术}

随着分子检测技术水平的提高, 基因检测和分 析手段越来越多。目前, 粪便 RNA 的检测技术主要 包括基于 PCR 的检测技术和基于基因芯片的检测技 术。这两种技术也是目前发展比较成熟的基因表达 量分析方法。

\section{1 基于PCR的检测技术}

基于 PCR 检测粪便 RNA 的技术主要包括 RT-PCR 技术和实时菼光定量 PCR 技术。RT-PCR 就 是将 mRNA 逆转录为 CDNA 的反应和 PCR 在一个 体系内进行, 即两步反应通过一步完成。RT-PCR 的 产物可以通过电泳进行检测并且依据电泳条带的大 小和亮度进行半定量。2005 年至 2008 年, Huang 研

表 2 两种粪便 RNA 提取方法的优缺点对比

\begin{tabular}{lll}
\hline \multicolumn{1}{c}{ 提取方法 } & \multicolumn{1}{c}{ 优点 } & 缺点 \\
\hline 富集肿瘤细胞 & 1. 提取的 RNA 来自于脱落细胞, 其纯度较高; & 1. 提取操作反应时间长、步骤多, 整个过程复杂和繁琐; \\
后提取 RNA & 2. 从活细胞中提取 RNA, 其质量较好。 & 2. 方法成本较高。 \\
直接提取粪便中 RNA & $\begin{array}{l}\text { 1. 提取操作快速、简便, 具有广泛应用前景; } \\
\text { 2. 方法成本较低。 }\end{array}$ & $\begin{array}{l}\text { 1. 提取的 RNA 可能含有细菌 RNA; } \\
\text { 2. 提取的 RNA 可能会有一定程度的降解。 }\end{array}$ \\
\hline
\end{tabular}


究小组 $24,32,33]$ 用RT-PCR分析了粪便RNA中 3 种和 大肠癌相关的基因, 即 CK19 基因、RPL19 基因和 $H E C A$ 基因。这 3 种基因的相对表达量在大肠癌患者 和正常人之间存在差异。Lagerholm等 ${ }^{[21]}$ 也利用 RT-PCR分析了 $c-m y c$ 基因在粪便RNA中的相对表达 量。

实时苂光定量 PCR 是 1996 年由美国Applied Biosystems公司推出的一种新技术。它不仅实现了 PCR从定性到定量的飞跃, 而且与常规 PCR 相比, 具有灵敏度高、特异性强的特点。实时苂光定量PCR 主要通过分析CDNA的含量, 从而得到相应的mRNA 表达量的变化。Ahmed等 ${ }^{[10]}$ 用实时苂光定量PCR技 术定量分析了粪便RNA中 8 种大肠癌相关基因, 并 指出分析这 8 种基因表达量的高低可以动态监测肿 瘤的进展。Koga等 ${ }^{[9]}$ 也利用实时苂光定量PCR技术 成功分析了粪便RNA中 4 种大肠癌相关基因的表达 量变化。从其研究结果可见, 实时苂光定量PCR可以 更准确更灵敏的分析目的基因在粪便RNA中表达量 的变化。

\section{2 基于基因芯片的检测技术}

基因芯片技术是 20 世纪 90 年代发展起来的一 种可同时、快速分析大量基因信息的检测技术，该
技术因具有高通量、高并行性等特点而被广泛应用 于基因表达量的研究，从而打破了传统方法一次只 能研究一个基因的弊端。基因芯片技术的原理是将 大量的探针分子固定在固体支持物上后与标记的样 品分子进行杂交，通过检测每个探针分子的杂交信 号强度进而获取样品分子的数量和序列信息。

基因芯片技术可以同时分析大肠癌患者粪便中 大量基因的表达情况，从而为发现和篮查大肠癌的 标志基因提供了简便快速的手段。Yajima等 ${ }^{[26]}$ 利用基 因芯片从 14564 种基因中筛选出了 85 种可以用于大 肠癌检测的基因，并且用聚焦基因芯片(Focused microarray)分析了其中 9 种基因的表达量 (PAP、 REG1A、DEPE、SEPP1、RPL27A、ATP1B1、EEF1A1、 $S F N 、 P R S 11)$ 。聚焦基因芯片的基本步骤如图 $3^{[26]}$ 所 示：(1) 富集脱落细胞并提取RNA；（2）通过多重 RT-PCR扩增并标记目的基因的cDNA; (3) 将标记的 cDNA和芯片上固定的探针杂交; (4) 苂光扫描, 根 据信号强度判读每种基因的表达情况。Ahmed等 ${ }^{[25]}$ 同 样应用基因芯片技术分析了粪便RNA中 miRNA的表 达量变化, 并指出联合检测miRNA和mRNA可以为 大肠癌的早期诊断提供一种个体化的诊断方案。

无论是基于 PCR 的检测技术还是基于基因芯片 的检测技术，其原理都是采用“模拟”的扩增技术，即

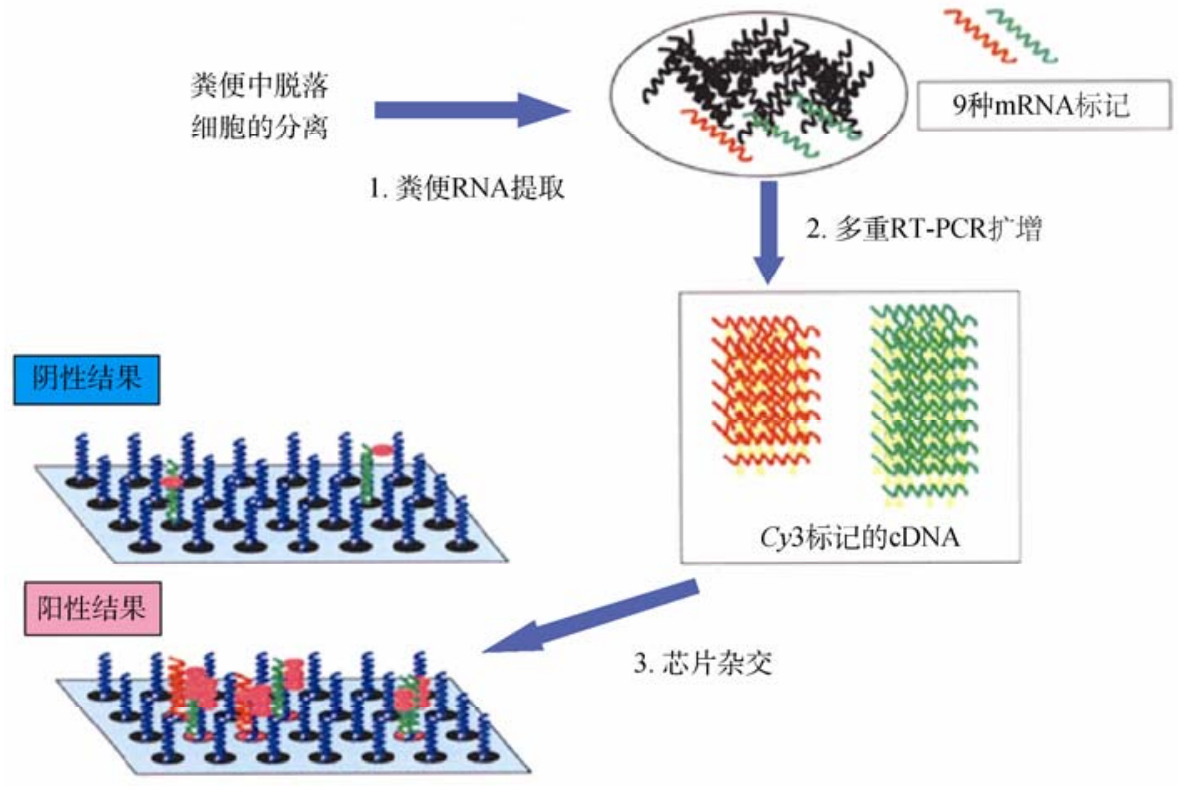

4. 苂光扫描

图 3 聚焦基因芯片原理图

整个过程包括 4 个步骤：(1) 粪便 RNA 提取；(2) 多重 RT-PCR 扩增并标记 CDNA； (3) 芯片杂交；(4) 苂光扫描。 
通过PCR一次扩增一种目的基因, 然后根据扩增产物 对应的信号强度来进行定量分析。而大肠癌的发生 和发展在遗传学上是多种基因改变和积累的过程, 至今研究人员没有发现一种明确的在大肠癌患者和 正常人中存在差异表达的基因, 而且在大肠癌早期, 一些癌基因呈低丰度表达。Yajima等 ${ }^{[26]}$ 和Takai等 ${ }^{[19]}$ 通过“模拟”的扩增技术(RT-PCR)联合多种基因检 测将灵敏度分别从原来的 52\%和 65\%提高到 78\%和 $90 \%$, 但是这种检测技术只是将每种基因的检测结 果合并在一起进行分析, 并不是真正意义的联合检 测。联合多基因检测应该是一次分析多种基因表达 量的总变化, 这样可以更有效地提高方法的灵敏度 和特异性, 而这种联合检测的要求可以通过“数字” 化的扩增原理得以实现。因此, 发展一种基于高灵 敏度“数字”化扩增原理并能够联合多种基因进行 检测的技术显得尤为重要。

\section{6 展 望}

尽管粪便 RNA 的检测为大肠癌早期诊断提供 了新的途径, 是大肠癌早期诊断的研究热点之一, 但是仍有许多问题亟待解决。如: (1) 粪便样本不易 保存; (2) 粪便 RNA 提取步骤复杂; (3) 粪便 RNA 检 测方法的灵敏度不够等。因此, 要使粪便 RNA 检测 真正成为大肠癌早期诊断的手段, 需要在以下 3 个 方面取得突破性进展。

\section{1 粪便样本的存储液}

为了能得到高质量的粪便 RNA, 从临床样本的 获得到提取操作开始, 整个提取过程都需要在低温 和短时间内完成。但是由于一些客观原因, 该过程 有时所需时间较长也很难一直保持低温条件。鉴于 此, 开发一种能够在常温下保存粪便样本的存储液, 使粪便中的脱落细胞不受粪便复杂环境的影响是十 分重要的。这样的存储液不但可以延长样本的存储 时间, 提高粪便 RNA 的提取质量, 而且可以使基于 粪便 RNA 检测的方法具有更广泛的应用前景。

\section{2 粪便RNA的自动化提取装置}

粪便是一种特殊的生物样品, 其异味会影响试 验者的操作效率。因此, 研制出一套可以同时处理 多个样本的自动化装置(即患者将新鲜的粪便样本 放入密闭的容器然后交给实验人员, 实验人员只需
将其放入自动化装置中就可完成样本处理全过程) 不仅有利于提高样本处理效率, 而且还可以加快粪 便 RNA 提取技术的推广和产业化。

\section{3 粪便RNA的数字化检测技术}

目前粪便RNA的检测技术都是基于“模拟”扩 增技术, 由于这些技术受仪器检测灵敏度和实验背 景的影响, 结果的准确度和灵敏度受到限制。最近, Margulies等 ${ }^{[34]}$ 基于“数字” 化扩增原理发展了一种 以单个分子为模板, 并列进行PCR扩增的技术。该技 术的每种PCR产物分别来源于一分子模板, 实现了 单分子扩增。鉴于此, 这种技术可以应用于粪便 RNA多种基因的联合检测并且具有较高的灵敏度。例 如, 某样本中有 10000 个cDNA分子, 将这 10000 个 CDNA分子进行独立和并列的PCR扩增反应, 然后 采用流式细胞仪或者芯片扫描对扩增产物进行解码, 就可以准确计算出不同CDNA分子的相对数量。该技 术已成功用于大规模DNA测序中, 若能成功用于粪 便RNA表达量的分析, 则可以提高大肠癌早期诊断 的灵敏度和特异性。

总之, 粪便 RNA 的检测是目前大肠癌篮查技术 的研究趋势和研究热点之一。相信随着大肠癌分子 机制研究的不断进展以及分子生物学技术的不断进 步, 粪便 RNA 的检测将成为临床无创性早期诊断大 肠癌的方法。

\section{参考文献(References):}

[1] Dodd GD. Epidemiology and economic impact of colon cancer. American College of Radiology, 1990, 13.

[2] Kahi CJ, Imperiale TF, Juliar BE, Rex DK. Effect of screening colonoscopy on colorectal cancer incidence and mortality. Clin Gastroenterol Hepatol, 2009, 7(7): 770-775.[DOI]

[3] Mandel JS, Church TR, Ederer F, Bond JH. Colorectal cancer mortality: effectiveness of biennial screening for fecal occult blood. J Natl Cancer Inst, 1999, 91(5): 434-437.[DOI]

[4] Smith RA, Cokkinides V, Brooks D, Saslow D, Brawley OW. Cancer screening in the United States, 2010: a review of current American cancer society guidelines and issues in cancer screening. CA Cancer J Clin, 2010, 60(2): 99-119.[DOI]

[5] Huang J, Kirk B, Favis R, Soussi T, Paty P, Cao W, Barany F. An endonuclease/ligase based mutation scanning method especially suited for analysis of neoplastic tissue. Oncogene, 2002, 21(12): 1909-1921.[DOI] 
[6] Li M, Diehl F, Dressman D, Vogelstein B, Kinzler KW. BEAMing up for detection and quantification of rare sequence variants. Nat Method, 2006, 3(2): 95-97.[DOI]

[7] Zou H, Taylor WR, Harrington JJ, Hussain FT, Cao X, Loprinzi CL, Levine TR, Rex DK, Ahnen D, Knigge KL, Lance P, Jiang X, Smith DI, Ahlquist DA. High detection rates of colorectal neoplasia by stool DNA testing with a novel digital melt curve assay. Gastroenterology, 2009, 136(2): 459-470. [DOI]

[8] Sjöblom T, Jones S, Wood LD, Parsons DW, Lin J, Barber TD, Mandelker D, Leary RJ, Ptak J, Silliman N, Szabo S, Buckhaults P, Farrell C, Meeh P, Markowitz SD, Willis J, Dawson D, Willson JK, Gazdar AF, Hartigan J, Wu L, Liu C, Parmigiani G, Park BH, Bachman KE, Papadopoulos N, Vogelstein B, Kinzler KW, Velculescu VE. The consensus coding sequences of human breast and colorectal cancers. Science, 2006, 314(5797): 268-274.[DOI]

[9] Koga Y, Yasunaga M, Moriya Y, Akasu T, Fujita S, Yamamoto S, Kozu T, Baba H, Matsumura Y. Detection of colorectal cancer cells from feces using quantitative real-time RT-PCR for colorectal cancer diagnosis. Cancer Sci, 2008, 99(10): 1977-1983.

[10] Ahmed FE, Vos PW, Ijames S, Lysle DT, Flake G, Sinar DR, Naziri W, Marcuard SP. Standardization for transcriptomic molecular markers to screen human colon cancer. Cancer Genomics Proteomics, 2007, 4(6): 419-431.

[11] Juretzka MM, Jensen KC, Longacre TA, Teng NN, Husain A. Detection of pelvic lymph node micrometastasis in stage IA2-IB2 cervical cancer by immunohistochemical analysis. Gynecol Onco, 2004, 93(1): 107-111.[DOI]

[12] Yang SH, Chien CC, Chen CW, Li SY, Huang CJ. Potential of faecal RNA in diagnosing colorectal cancer. Cancer Lett, 2005, 226(1): 55-63.[DOI]

[13] Osborn NK, Ahlquist DA. Stool Screening for Colorectal Cancer: Molecular Approaches. Gastroenterology, 2005, 128(1): 192-206.[DOI]

[14] Shao J, Sheng H, Inoue H, Morrow JD, DuBois RN. Regulation of constitutive cyclooxygenase-2 expression in colon carcinoma cells. J Biol Chem, 2000, 275(43): 33951-33956.[DOI]

[15] Yamauchi T, Watanabe M, Kubota T, Hasegawa H, Ishii Y, Endo T, Kabeshima Y, Yorozuya K, Yamamoto K, Mukai M, Kitajima M. Cyclooxygenase-2 expression as a new marker for patients with colorectal cancer. Dis Colon Rectum, 2002, 45(1): 98-103.[DOI]

[16] Wu AW, Gu J, Ji JF, Li ZF, Xu GW. Role of COX-2 in carcinogenesis of colorectal cancer and its relationship with tumor biological characteristics and patients' prognosis. World J Gastroenterol, 2003, 9(9): 1990-1994.

[17] Kanaoka S, Yoshida K, Miura N, Sugimura H, Kajimura M. Potential usefulness of detecting cyclooxygenase 2 messenger
RNA in feces for colorectal cancer screening. Gastroenterology, 2004, 127(2): 422-427.[DOI]

[18] Zucker S, Vacirca J. Role of matrix metalloproteinases (MMPs) in colorectal cancer. Cancer Metastasis Rev, 2004, 23: 101-117.[DOI]

[19] Takai T, Kanaoka S, Yoshida K, Hamaya Y, Ikuma M, Miura N, Sugimura H, Kajimura M, Hishida A. Fecal cyclooxygenase 2 plus matrix metalloproteinase 7 mRNA assays as a marker for colorectal cancer screening. Cancer Epidemiol Biomarkers Prev, 2009, 18(6): 1888-1893.[DOI]

[20] He TC, Sparks AB, Rago C, Hermeking H, Zawel L, da Costa LT, Morin PJ, Vogelstein B, Kinzler KW. Identification of c-MYC as a target of the APC pathway. Science, 1998, 281(5382): 1509-1512.[DOI]

[21] Lagerholm S, Dutta S, Nair P. Non-invasive detection of c-myc p64, c-myc p67 and c-erbb-2 in colorectal cancer. Scand J Gastroenterol, 2005, 40(11): 1343-1350.[DOI]

[22] Zhang JC, Wang ZR, Cheng YJ, Yang DZ, Shi JS, Liang AL, Liu NN, Wang XM. Expression of proliferating cell nuclear antigen and CD44 variant exon 6 in primary tumors and corresponding lymph node metastases of colorectal carcinoma with Dukes' stage C or D. World J Gastroenterol, 2003, 9(7): 1482-1486.

[23] Yamao T, Matsumura Y, Shimada Y, Moriya Y, Sugihara K, Akasu T, Fujita S, Kakizoe T. Abnormal expression of CD44 variants in the exfoliated cells in the feces of patients with colorectal cancer. Gastroenterology, 1998, 114(6): 1196-1205.[DOI]

[24] Slaby O, Svoboda M, Michalek J, Vyzula R. MicroRNAs in colorectal cancer: translation of molecular biology into clinical application. Mol Cancer, 2009, 8: 102.

[25] Ahmed FE, Jeffries CD, Vos PW, Flake G, Nuovo GJ, Sinar DR, Naziri W, Marcuard SP. Diagnostic microRNA markers for screening sporadic human colon cancer and active ulcerative colitis in stool and tissue. Cancer Genomics Proteomics, 2009, 6(5): 281-295.[DOI]

[26] Yajima S, Ishii M, Matsushita H, Aoyagi K, Yoshimatsu K, Kaneko H, Yamamoto N, Teramoto T, Yoshida T, Matsumura Y, Sasaki H. Expression profiling of fecal colonocytes for RNA-based screening of colorectal cancer. Int J Oncol, 2007, 31(5): 1029-1037.

[27] Loktionov A. Cell exfoliation in the human colon: myth, reality and implications for colorectal cancer screening. Int $J$ Cancer, 2007, 120(11): 2281-2289. [DOI]

[28] Davies RJ, Freeman A, Morris LS, Bingham S, Dilworth S, Scott I, Laskey RA, Miller R, Coleman N. Analysis of minichromosome maintenance proteins as a novel method for detection of colorectal cancer in stool. Lancet, 2002, 359: 1917-1919.[DOI]

[29] Ahmed FE, Vos P. Molecular markers for human colon cancer in stool and blood identified by RT-PCR. Anticancer Res, 
2004, 24(6): 4127-4134.

[30] Matsushita H, Matsumura Y, Moriya Y, Akasu T, Fujita S, Yamamoto S, Onouchi S, Saito N, Sugito M, Ito M, Kozu T, Minowa T, Nomura S, Tsunoda H, Kakizoe T. A new method for isolating colonocytes from naturally evacuated feces and its clinical application to colorectal cancer diagnosis. Gastroenterology, 2005, 129(6): 1918-1927.[DOI]

[31] Chomczynski P, Sacchi N. The single-step method of RNA isolation by acid guanidinium thiocyanate-phenol-chloroform extraction: twenty-something years on. Nat Protoc, 2006, 1(2): 581-585.

[32] Chien CC, Chang CC, Yang SH, Chen SH, Huang CJ. A homologue of the Drosophila headcase protein is a novel tumor marker for early-stage colorectal cancer. Oncol Rep, 2006, 15(4): 919-926.

[33] Huang CJ, Chien CC, Yang SH, Chang CC, Sun HL, Cheng
YC, Liu CC, Lin SC, Lin CM. Faecal ribosomal protein L19 is a genetic prognostic factor for survival in colorectal cancer. J Cell Mol Med, 2008, 12(5B): 1936-1943.

[34] Margulies M, Egholm M, Altman WE, Attiya S, Bader JS, Bemben LA, Berka J, Braverman MS, Chen YJ, Chen Z, Dewell SB, Du L, Fierro JM, Gomes XV, Godwin BC, He W, Helgesen S, Ho CH, Irzyk GP, Jando SC, Alenquer ML, Jarvie TP, Jirage KB, Kim JB, Knight JR, Lanza JR, Leamon JH, Lefkowitz SM, Lei M, Li J, Lohman KL, Lu H, Makhijani VB, McDade KE, McKenna MP, Myers EW, Nickerson E, Nobile JR, Plant R, Puc BP, Ronan MT, Roth GT, Sarkis GJ, Simons JF, Simpson JW, Srinivasan M, Tartaro KR, Tomasz A, Vogt KA, Volkmer GA, Wang SH, Wang Y, Weiner MP, Yu P, Begley RF, Rothberg JM. Genome sequencing in microfabricated high-density picolitre reactors. Nature, 2005, 437(7057): 376-380.[DOI]

\section{・遗传咨询・}

\section{欢迎订阅 2011 年《基因组学与应用生物学》}

《基因组学与应用生物学》是由广西大学主管和主办, 公开发行的双月刊科学期刊。广西大学聘请中国农业大学 李宁院士任主编，北京大学教授朱玉贤博士和海南省热带农业资源研究所所长方宣钧博士任执行主编，国内众多的著 名学者出任编委。

《基因组学与应用生物学》主要刊登现代生物技术的前沿学科和基础学科如基因组学、分子细胞遗传学、生化与 分子生物学、应用生物学等相关的原始研究成果。刊登植物、动物及微生物领域的生物在组织、器官、细胞、染色体、 蛋白质、基因、酶、发酵工程等不同水平上的现代生物技术等基础与应用基础研究的成果。本刊按国际标准编排，题 目摘要、图表、引用文献等均实行中英文对照, 实现网上领先发表模式。

《基因组学与应用生物学》, 前身是原《广西农业大学学报》, 创刊于 1982 年。广西农业大学合并入广西大学以后 更名为《广西农业生物科学》。《广西农业生物科学》已入编《中文核心期刊要目总览》2008 年版 (即第五版) 之综合 性农业科学类的核心期刊，是中国科学引文数据库(CSCD)来源期刊，也是中国科技核心期刊即中国科技论文统计源期 刊。2001 年入选国家新闻出版总署 “中国期刊方阵”, 先后被国际知名检索系统一一英国国际农业与生物科学研究中心 $(\mathrm{CABI}) 、$ 美国《化学文摘》(CA)、美国《剑桥科学文摘 : 自然科学》(CSA : NS)、英国《动物学记录》(ZR)、俄罗斯 《文摘杂志》(AJ)等收录。

承载着《广西农业生物科学》的历史与荣誉, 《基因组学与应用生物学》将在新的高度开拓奋进, 为现代生命科学 和应用生物学的研究与发展提供学术交流的平台，使之成为中国科学家走向世界的桥梁。

《基因组学与应用生物学》《Genomics and Applied Biology》, ISSN1674-568X, CN45-1369/Q, 双月刊, 双月 28 日出版, 国内定价：人民币 $¥ 40.00 /$ 期 ，人民币 $¥ 240.00 /$ 年 ; 国际定价 : 美元 $\$ 40.00 /$ 期 ，美元 $\$ 240.00 /$ 年。

\section{邮局汇款}

地 址：广西南宁市大学东路 100 号广西大学西校园榕江路《基因组学与应用生物学》编辑部

收款单位 : 《基因组学与应用生物学》编辑部

邮编 : 530004

联系电话：0771-3239102，0771-3232621

传 真 : 0771-3232621

E-mail: gab@hibio.org; gab@genoapplbiol.org

网 址: www.genoapplbiol.org 